\title{
Variability in Morphology and Growth Characteristics of Different Isolates of Entomopathogenic Fungi Managing the Mealy Bugs Maconellicocus hirsutus
}

\author{
S.B. Sable ${ }^{1 *}$, P.B. Deore ${ }^{1}$, H.V. Deshmukh², H.N. Markad ${ }^{2}$ and G.B. Jejurkar $^{2}$ \\ ${ }^{1}$ College of Agricultur, Dhule, Plant Pathology Section, MPKV, Rahuri, Maharashtra, India \\ ${ }^{2}$ Department of Plant Pathology, PGI, MPKV, Rahuri, Maharashtra, India \\ *Corresponding author
}

\begin{abstract}
Keywords
Entomopathogenic fungi, Cadaver, Aspergillus spp., Colony diameter, Spores shape, PDA media, Maconellicoccus hirsutus
\end{abstract}

Article Info

Accepted:

18 February 2019

Available Online:

10 March 2019

\section{A B S T R A C T}

Current research efforts are directed towards native entomopathogenic fungi which are highly virulent to insect pests to develop efficient and eco-friendly bio-pesticides. From the insect cadavers fifteen different fungal isolates were isolated on DOC2-50\% selective media and were identifying as isolates of Aspergillus tamari, A. niger and A. flavus. All the fifteen isolates showed variation in all the morphological characters studied. Highest mean colony diameter $(\mathrm{mm})$ was reported in isolate EPF-14 at all the time intervals. The lowest mean colony diameter $(\mathrm{mm})$ was reported in isolate EPF-13 at 24, 72 and $96 \mathrm{hr}$ interval while at $48 \mathrm{hrs}$ the lowest mean colony diameter $(\mathrm{mm})$ was reported in isolate EPF-9. The most of the isolates were not produced any colony pigmentation on PDA media. The isolates EPF-12 and EPF-15 were grayish green color, while EPF-1 and EPF-7 observed light grayish green color. The isolate EPF-5 was dark grayish green color while, EPF-13 was yellowish grayish green color. The isolates EPF-9 \& EPF-11 were dull whitish green color and isolate EPF-6 \& EPF-8 were dark green and bluish green color respectively. The isolates EPF-2 \& EPF-14 were black in color while, isolates EPF-4, EPF-3 \& EPF-10 were dark black, light black and bluish black in color respectively. Among all the isolates, the isolates EPF-1, EPF-4, EPF-5, EPF-6, EPF-7, EPF-9, EPF-11, EPF-12, EPF-13 \& EPF-15 produced the concentric rings while, in isolate EPF-2, EPF-3, EPF-8, EPF-10 \& EPF-14 concentric rings were absent. Isolates showed variation in the spore's shape, size and colours. The spore shape was varying from round to globose. While, spore size was varying from to $10.1 \times 9.7=97.97 \mu$ to $4.3 \times 4.2=18.06 \mu$ and length width ratio varies from 1.06 to 1.00 . The colour of spores was varies from brown to yellow except in isolate EPF-1, EPF-11 and EPF-13.

\section{Introduction}

The knowledge of entomopathogenic fungi dates back for several centuries (McCoy et al., 1988). Pasteur (1874) was one of the first to suggest that microorganisms could be used to control insect pests. Numerous groups of entomopathogenic fungi were described during the $19^{\text {th }}$ century. One of the earliest successes in biocontrol was the use of Aschersonia aleyrodes to control citrus white flies in Florida (Berger, 1921). 
Many genera of entomopathogenic fungi are being used in agricultural crop pest management such as Lower fungi i.e. Mastigomycotina, Ascomycotina, Basidomycotina and fungi imperfecti which includes several genera like Aspergillus, Beauveria, Metarhizium, Nomuraea, Paecilomyces, Penicillium, Trichoderma, Verticillium etc which suppress the diverse group of insect pest such as coleopterans, lepidopterous, sucking pest. Amongst these, several asexual stages of fungi are associated with insect infection. There are approximately 750 species of fungi from 56 genera that infect arthropods. These are ubiquitous and in appropriate hosts are capable of natural recycling (Hajek and Leger, 1994; Alexopoulos et al., 1996).

Recently increased use of conventional chemical pesticides over the years has not only contributed to an increase in food production, but also has resulted in adverse effects on the environment and non-target organisms. In view of these side effects, the necessity for sustainable crop production through eco-friendly pest management technique is being largely felt in the recent times. Hence, the present investigation was planned and carried out, to study the morphology and growth characteristics of different isolates of entomopathogenic fungi.

\section{Materials and Methods}

\section{Survey}

The field survey was conducted in Dhule, Nandurbar, Jalgaon, Nasik and Beed districts of Maharashtra (India) during kharif, 2014 to collect the insect cadavers from fields and forest areas and nineteen insect cadavers infected with fungus were collected and placed in separate plastic containers of $6 \times 4$ $\mathrm{cm}$ size. Collected insect cadavers were brought to section laboratory for further study.

\section{Isolation of entomopathogenic fungi}

The selective media DOC2-50\% (Shin et.al., 2010) was prepared for the isolation of pure cultures entomopathogenic fungi. The infected portion of each insect cadaver was cut into small bits and a small portion of infected tissue was transferred aseptically to a culture plate containing DOC2-50\% selective media having Bactopeptone $3.0 \mathrm{~g}, \mathrm{CuCl} 20.1$ $\mathrm{g}$, Crystal violet $2.0 \mathrm{mg}$, Agar $15.0 \mathrm{~g}$ distilled water $1000 \mathrm{ml} \mathrm{pH}$ with $\mathrm{HCl}$ 4. The inoculated culture plates were incubated at $28 \pm 2^{\circ} \mathrm{C}$ in BOD incubator and kept under constant observation for the growth and development of fungus. Three to five days after incubation, the fungus growth was purified by sub-culturing and slants of each purified fungus culture were prepared.

\section{Pathogenicity test}

To determine the pathogenicity of isolated fungal isolates over the insect, the mealy bugs (Maconellicocus hirsutus) were reared on their natural diet (pumpkin) in Biocontrol Laboratory, Agril. Entomology Section, College of Agriculture, Dhule. Surface sterilization of rearing containers were carried with $10 \%$ formaldehyde to prevent bacterial contamination of the healthy stock.

The spore suspension of $10^{-3}$ spores $/ \mathrm{ml}$ of each fungus isolate was prepared by mixing harvested spores with distilled water and 0.2 per cent Tween-80. The spore suspensions of all isolates were applied on adult mealy bug by direct dipping method. The adult mealy bugs were dipped in spore suspension for 30 seconds.

For the pathogenicity test of each fungus isolate 10 adult mealy bugs were used and another set was kept without addition of spores as control. The inoculated mealy bugs were placed on surface sterilized sprouted 
potato in Petri plate lined with wet blotting paper and incubated at $28 \pm 2{ }^{\circ} \mathrm{C}$ in $\mathrm{BOD}$ incubator. Dead mealy bugs were transferred into humidity chamber to monitor any fungal out-growth as detected on insect cadavers collected during the survey. Then the fungus isolates were reisolated from the inoculated mealy bugs on DOC2-50\% selective media.

\section{Identification of entomopathogenic fungi isolates}

The purified coded fungus isolates were sent to Indian Type Culture Collection, Division of Plant Pathology, Indian Agricultural Research Institute, New Delhi - 110012 for identification.

\section{Morphology and growth characteristics of entomopathogenic fungi isolates}

Morphology and growth characteristics of entomopathogenic fungi isolates were studied on PDA media. Observations on morphological and growth characteristics of individual isolates of Radial growth, Colony color, Colony diameter, Concentric rings/circles (Zonetion), Colony surface layer, Colony pigmentation, Appearance of growth, Shape of spores, Colour of spores, Size of spores, Length and width ratio of spores were recorded after 7 days incubation at $28 \pm 2^{\circ} \mathrm{C}$.

\section{Results and Discussion}

During the survey, different locations were surveyed and nineteen insect cadavers infected with fungus were collected and brought to section laboratory. Out of nineteen samples inoculated only fifteen samples showed the growth of fungus on DOC2-50\% selective media. No any fungus was isolated from samples EPF-16, EPF-17, EPF-18 and EPF-19. Therefore, the fungal isolates EPF-1 to EPF-15 were taken for the further study and were purified by sub-culturing and maintained on Potato Dextrose Agar (PDA) slants.

The variations in colony diameter of all fifteen isolates of entomopathogenic fungi on PDA media at 24, 48 and $72 \mathrm{hrs}$ were found statistically significant. There was significant variation between isolates and time interval. The results are presented in (Table 1; Plate 1; Fig. 1).

At $24 \mathrm{hrs}$ all the fifteen isolates show statistically significant variation in colony diameter on PDA media. While, comparing the highest growth rate, the isolate EPF-14 $(22 \mathrm{~mm})$ had recorded the highest colony diameter on PDA media and the lowest colony diameter was recorded in EPF-13 (14mm).

At $48 \mathrm{hrs}$ all the fifteen isolates showed statistically significant variation in colony diameter on PDA media. The isolate EPF-14 (38.66mm) had recorded the highest colony diameter on PDA media and the lowest colony diameter was recorded in EPF-9 (26.66 mm).

At $72 \mathrm{hrs}$ all the fifteen isolates showed statistically significant variation in colony diameter on PDA media. The isolate EPF-14 $(60.00 \mathrm{~mm})$ had recorded the highest colony diameter on PDA media and the lowest colony diameter was recorded in EPF-13 $(44.00 \mathrm{~mm})$. At $96 \mathrm{hrs}$ all the fifteen isolates showed statistically significant variation in colony diameter on PDA media. The isolate EPF-14 and EPF-2 $(86.33 \mathrm{~mm})$ had recorded the highest colony diameter on PDA media and the lowest colony diameter was recorded in EPF-13 (59.00mm). The results presented in Table 2 showed that radial growth was present in all fifteen isolates of entomopathogenic fungi isolates on PDA media. The colony color of each isolate was recorded at $96 \mathrm{hrs}$ on PDA media by visual 
observation. The results presented in Table 2 showed that all the fifteen isolates showed variation in colony color on PDA media. All the fifteen isolates were visually differentiated in three main color categories viz., grayish green, green and black. The concentric rings of each isolate were recorded at $96 \mathrm{hrs}$ on PDA media. The results presented in Table 2 showed that all the fifteen isolates showed variation in concentric rings on PDA media. Colony pigmentation of seven days old cultures grown on PDA media was recorded. The result was presented in Table 2 showed that in most of the isolates pigmentation was absent. Appearance of growth of all the isolates of entomopathogenic fungi was recorded at $96 \mathrm{hrs}$ on PDA media. Results were presented in Table 2 showed the variation in appearance of growth on PDA media.

After incubation up to seven days, the shapes of ten spores per isolate were recorded under microscope. The results are presented in (Table 3) showed that the shape of spores varies from round to globose. After incubation up to seven days, the colours of ten spores were recorded by visual observations. The result is presented in Table 3 showed that the colours of spores varies from brown to yellow except in isolate EPF-1, EPF-11 and EPF-13. The data presented in Table 3 showed variation in size of spores among all the fifteen isolates on PDA media. The isolate EPF-15 produced the biggest size spores (10.1 x 9.7 $\mu)$ followed by EPF-1 $(9.1 \times 9.1 \mu)$ while smallest size spores were produced by the isolate EPF-8 fallowed by EPF-10 and EPF-9. On the basis of data presented in Table 3, the spores were grouped in three categories viz., small size spores $(\leq 33 \mu)$, medium size spores $(>33$ to $\leq 66 \mu)$ and large size spores $(>66 \mu)$. The data presented in Table 3 showed the variation in length/width ratio of spores among all the fifteen isolates.

Table.1 Variability in colony diameter of entomopathogenic fungi isolates

\begin{tabular}{|c|c|c|c|c|c|}
\hline \multirow{2}{*}{$\begin{array}{l}\text { Sr. } \\
\text { No. }\end{array}$} & \multirow[t]{2}{*}{ Isolates } & \multicolumn{4}{|c|}{ Colony diameter $(\mathrm{mm})$ at different time intervals } \\
\hline & & $\begin{array}{c}24 \text { hr. } \\
\text { (Mean) }\end{array}$ & $\begin{array}{l}48 \mathrm{hr} . \\
\text { (Mean) }\end{array}$ & $\begin{array}{l}72 \mathrm{hr} . \\
\text { (Mean) }\end{array}$ & $\begin{array}{l}96 \mathrm{hr} . \\
\text { (Mean) }\end{array}$ \\
\hline 1 & EPF-1 & 17.33 & 33.33 & 45.00 & 65.66 \\
\hline 2 & EPF-2 & 16.00 & 37.00 & 56.33 & 86.33 \\
\hline 3 & EPF-3 & 19.33 & 33.33 & 57.33 & 81.66 \\
\hline 4 & EPF-4 & 15.00 & 32.83 & 55.00 & 80.16 \\
\hline 5 & EPF-5 & 18.33 & 34.33 & 47.33 & 64.66 \\
\hline 6 & EPF-6 & 16.67 & 33.66 & 45.33 & 60.50 \\
\hline 7 & EPF-7 & 18.33 & 36.66 & 47.00 & 63.50 \\
\hline 8 & EPF-8 & 19.00 & 35.66 & 58.66 & 73.00 \\
\hline 9 & EPF-9 & 15.67 & 26.66 & 47.00 & 63.83 \\
\hline 10 & EPF-10 & 15.33 & 30.66 & 52.00 & 69.83 \\
\hline 11 & EPF-11 & 17.33 & 35.66 & 45.00 & 60.66 \\
\hline 12 & EPF-12 & 17.00 & 30.66 & 47.66 & 67.33 \\
\hline 13 & EPF-13 & 14.00 & 30.00 & 44.00 & 59.00 \\
\hline 14 & EPF-14 & 22.00 & 38.66 & 60.00 & 86.83 \\
\hline 15 & EPF-15 & 19.00 & 33.00 & 45.00 & 61.83 \\
\hline & SE \pm & 0.49 & 0.94 & 1.41 & 0.63 \\
\hline & CD@5\% & 1.42 & 2.71 & 4.06 & 1.81 \\
\hline
\end{tabular}


Table.2 Variability in colony characteristics of entomopathogenic fungi isolates

\begin{tabular}{|c|c|c|c|c|c|c|}
\hline \multirow[b]{2}{*}{ Isolates } & \multicolumn{6}{|c|}{ Colony characteristics } \\
\hline & $\begin{array}{l}\text { Radial } \\
\text { growth }\end{array}$ & Colony color & $\begin{array}{l}\text { Concentric } \\
\text { rings }\end{array}$ & Colony surface layer & $\begin{array}{c}\text { Colony } \\
\text { pigmentation }\end{array}$ & $\begin{array}{c}\text { Appearance } \\
\text { of growth }\end{array}$ \\
\hline EPF-1 & Present & Light grayish green & Present & Mass like mat & Absent & BLMG \\
\hline EPF-2 & Present & Black & Absent & Flat but mass like mat & Light yellow & CTkMG \\
\hline EPF-3 & Present & Light black & Absent & Flat but mass like mat & Absent & CTkMG \\
\hline EPF-4 & Present & Dark black & Present & Flat but mass like mat & Absent & CTkMG \\
\hline EPF-5 & Present & Dark grayish green & Present & Mass like mat & Absent & BLMG \\
\hline EPF-6 & Present & Dark green & Present & Mass like mat & Light golden yellow & BLMG \\
\hline EPF-7 & Present & Light grayish green & Present & Mass like mat & Absent & BLMG \\
\hline EPF-8 & Present & Bluish green & Absent & Completely Flat & Light yellow & CTnMG \\
\hline EPF-9 & Present & Dull whitish green & Present & Cottony fussy & Absent & $\mathrm{TM}$ \\
\hline EPF-10 & Present & Bluish black & Absent & Flat but mass like mat & Absent & CTkMG \\
\hline EPF-11 & Present & Dull whitish green & Present & Cottony fussy & Light golden yellow & $\mathrm{TM}$ \\
\hline EPF-12 & Present & Grayish green & Present & Mass like mat & Absent & BLMG \\
\hline EPF-13 & Present & $\begin{array}{l}\text { Yellowish grayish } \\
\text { green }\end{array}$ & Present & Mass like mat & Absent & BLMG \\
\hline EPF-14 & Present & Black & Absent & Flat but mass like mat & Yellow light & CTkMG \\
\hline EPF-15 & Present & Grayish green & Present & Mass like mat & Absent & BLMG \\
\hline
\end{tabular}


Table.3 Variability in conidia characteristics of entomopathogenic fungi isolates

\begin{tabular}{|c|l|l|l|l|c|}
\hline \multirow{2}{*}{ Sr. No } & \multirow{2}{*}{ Isolates } & \multicolumn{1}{|c|}{ Shape } & \multicolumn{1}{|c|}{ Coloridia characteristics } \\
\hline $\mathbf{1}$ & EPF-1 & Round & $\begin{array}{l}\text { Light grayish } \\
\text { yellow }\end{array}$ & $9.1 \times 9.1=82.81$ & 1.00 \\
\hline $\mathbf{2}$ & EPF-2 & Round & Dark brown & $5.2 \times 5.2=27.04$ & 1.00 \\
\hline $\mathbf{3}$ & EPF-3 & Globose & Dark brown & $5.0 \times 4.9=24.50$ & 1.02 \\
\hline $\mathbf{4}$ & EPF-4 & Globose & Dark Brown & $4.6 \times 4.3=19.78$ & 1.06 \\
\hline $\mathbf{5}$ & EPF-5 & Globose & Light yellow & $9.0 \times 8.8=79.20$ & 1.02 \\
\hline $\mathbf{6}$ & EPF-6 & Globose & Light yellow & $6.4 \times 6.1=39.04$ & 1.05 \\
\hline $\mathbf{7}$ & EPF-7 & Globose & Light brown & $5.7 \times 5.6=31.92$ & 1.01 \\
\hline $\mathbf{8}$ & EPF-8 & Globose & Yellowish & $4.3 \times 4.2=18.06$ & 1.02 \\
\hline $\mathbf{9}$ & EPF-9 & Round & Dark brown & $4.4 \times 4.4=19.36$ & 1.00 \\
\hline $\mathbf{1 0}$ & EPF-10 & Globose & Dark brown & $4.4 \times 4.3=18.92$ & 1.02 \\
\hline $\mathbf{1 1}$ & EPF-11 & Round & Light green & $5.0 \times 5.0=25.00$ & 1.00 \\
\hline $\mathbf{1 2}$ & EPF-12 & Round & Light brown & $8.1 \times 8.1=65.61$ & 1.00 \\
\hline $\mathbf{1 3}$ & EPF-13 & Round & $\begin{array}{l}\text { Light yellow } \\
\text { green }\end{array}$ & $5.4 \times 5.4=29.16$ & 1.00 \\
\hline $\mathbf{1 4}$ & EPF-14 & Round & Dark brown & $6.0 \times 6.0=36.00$ & 1.00 \\
\hline $\mathbf{1 5}$ & EPF-15 & Globose & Light yellow & $10.1 \times 9.7=97.97$ & 1.04 \\
\hline
\end{tabular}

$\mathrm{L} / \mathrm{W}$ ratio $=$ Length to Width ratio

Fig.1 Variability in colony diameter of entomopathogenic fungi isolates

\begin{tabular}{|c|c|}
\hline 24 hr (Mean) & $\begin{array}{l}\square \text { EPF-1 } \\
\square \text { EPF-2 } \\
\square \text { EPF-3 } \\
\square \text { EPF-4 } \\
\square \text { EPF-5 } \\
\square \text { EPF-6 } \\
\square \text { EPF-7 } \\
\square \text { EPF-8 } \\
\square \text { EPF-9 } \\
\text { mEPF-10 } \\
\square \text { EPF-11 } \\
\square \text { EPF-12 } \\
\square \text { EPF-13 } \\
\square \text { EPF-14 } \\
\square \text { EPF-15 }\end{array}$ \\
\hline
\end{tabular}


Plate.1 Variability in colony characteristics of entomopathogenic fungi isolates

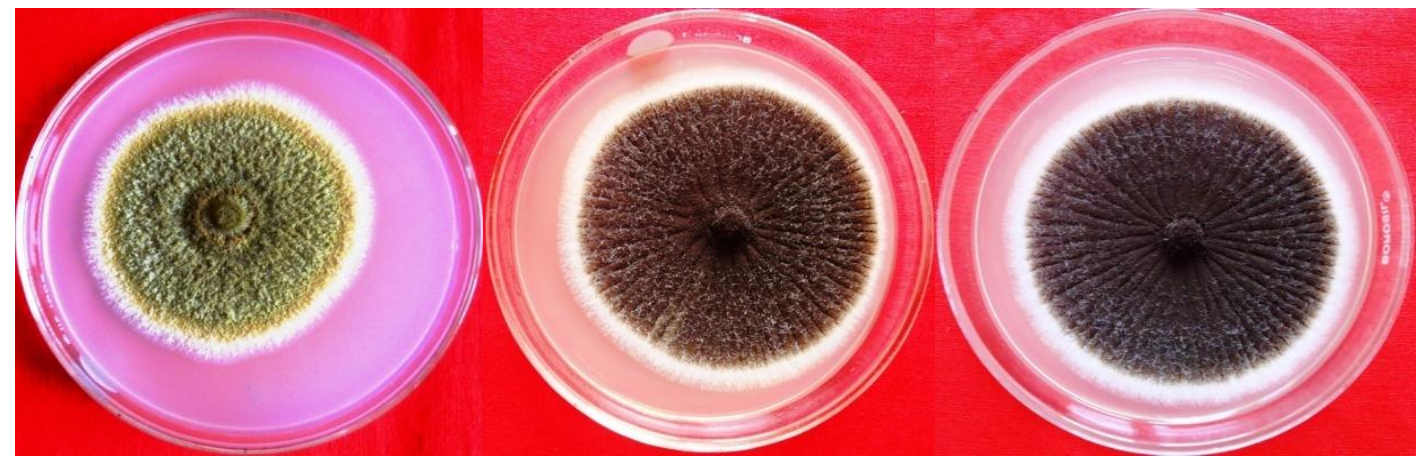

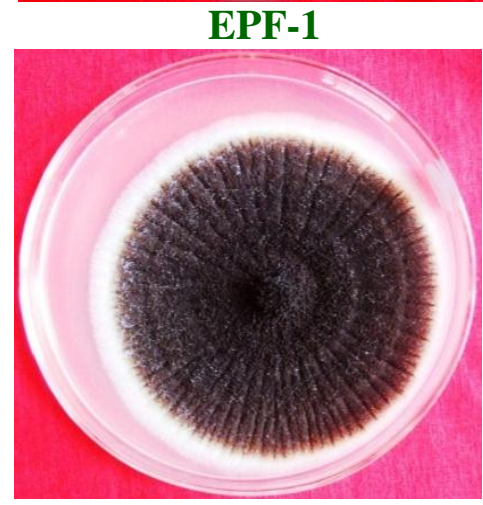

EPF-4

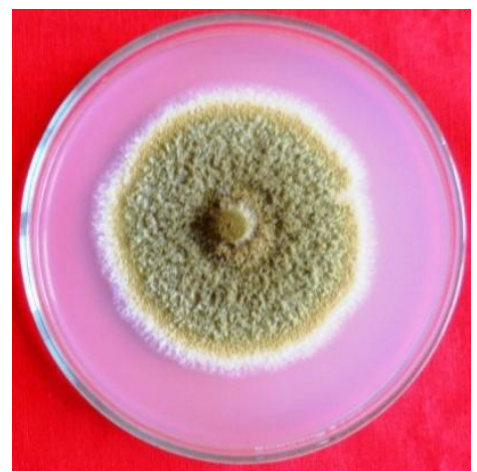

EPF-7

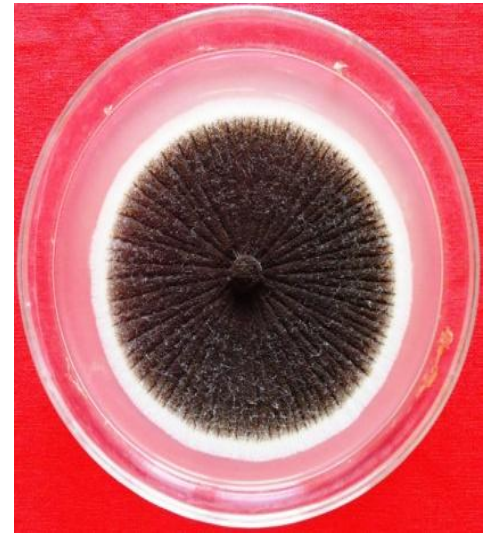

EPF-10
EPF-2

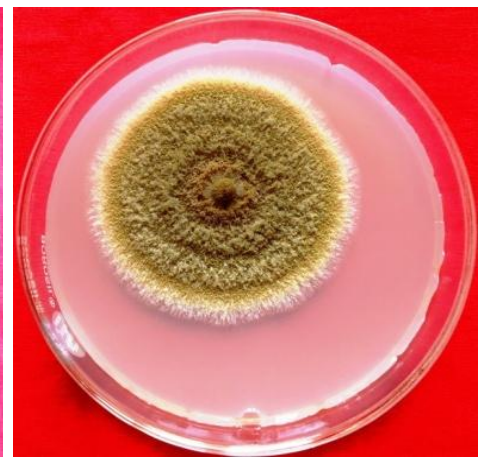

EPF-5

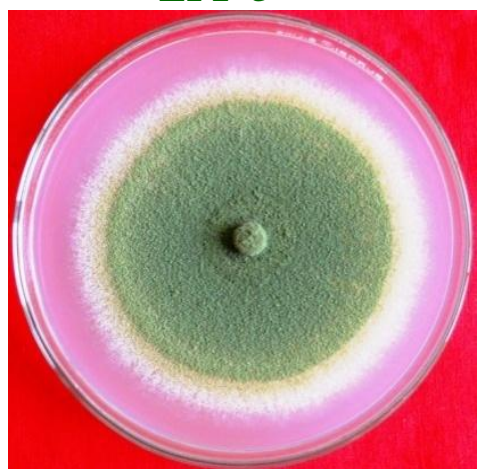

EPF-8

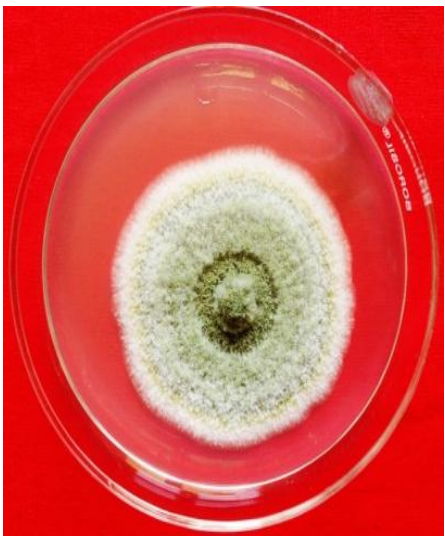

EPF-11
EPF-3

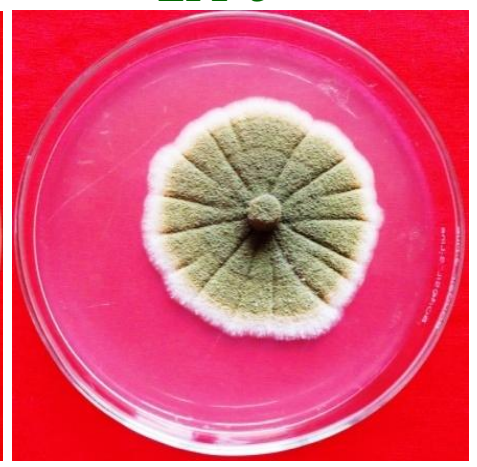

EPF-6

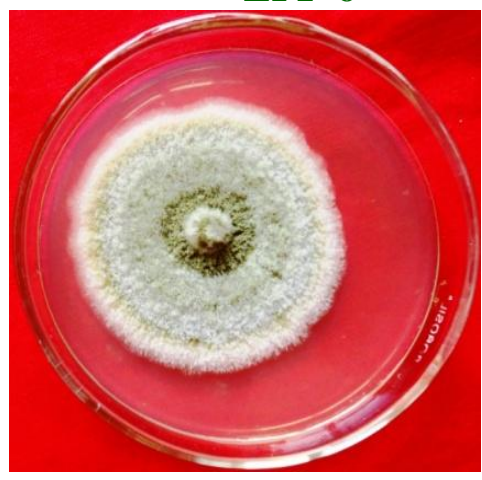

EPF-9

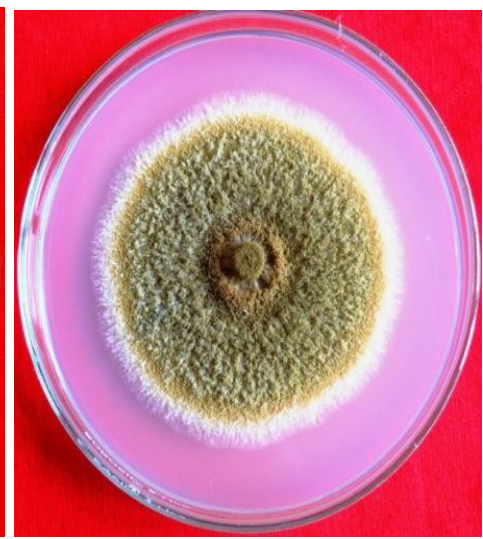

EPF-12 


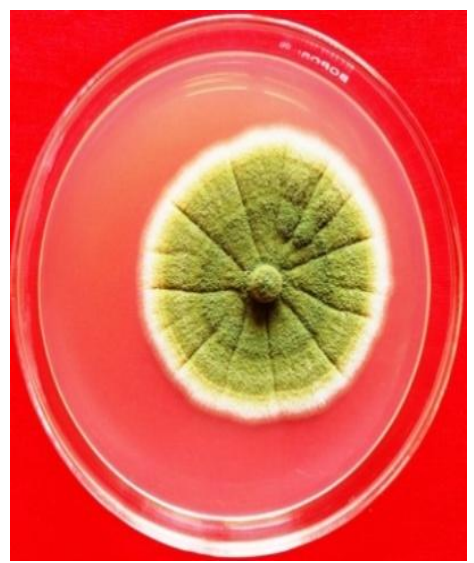

EPF-13

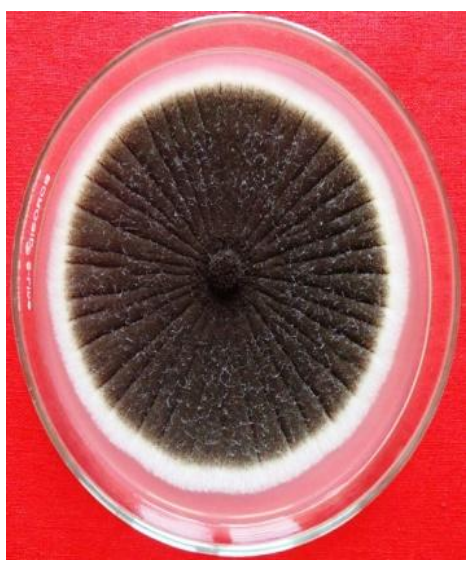

EPF-14

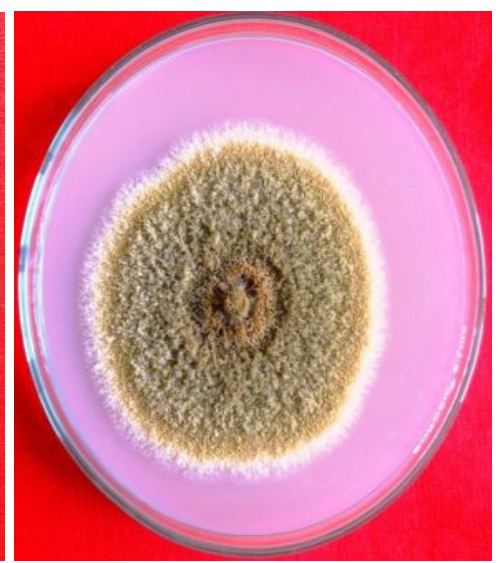

EPF-15
The highest length/width ratio of spores were observed in isolate EPF-4 (1.06). In addition to the fifteen isolates of entomopathogenic fungi were tested for their virulence against mealy bugs (Maconellicoccus hirsutus ) in vitro conditions at $10^{3}, 10^{6}$ and $10^{9}$ spore concentrate.

Studied entomopathogenic fungi isolates were evaluated at different spore concentration against mealy bugs and insect mortality was observed at $24 \mathrm{hr}$ interval after inoculation up to 10 days on red pumpkin in laboratory at room temperature.

The percent mortality was calculated by using following formula.

\begin{tabular}{|c|c|}
\hline & $\begin{array}{l}\text { Total no. of dead } \\
\text { mealy bug }\end{array}$ \\
\hline $\begin{array}{l}\text { Percent } \\
\text { mortality = }\end{array}$ & $\begin{array}{l}\text { Total no. } \begin{array}{l}\text { of } \\
\text { inoculated } \\
\text { bug }\end{array} \\
\text { mealy }\end{array}$ \\
\hline
\end{tabular}

Similar results with respect to variation in colony diameter and growth rate are reported by many workers. Nyongesa et al., (2015) and Odhiambo et al., (2013) observed the colonies of A. niger on MEA were date brown with white While, the colonies of A. flavus on MEA were yellow green with white mycelia at the edges; formed sporulation rings; did not produce exudates and soluble pigments; $A$. flavus strains had similar surface colour of olive green with whitish margins and reverse colour of creamish to yellow on PDA.

The spore shape was varying from round to globose. While, spore size was varying from to $10.1 \times 9.7=97.97 \mu$ to $4.3 \times 4.2=18.06 \mu$ and length width ratio varies from 1.06 to 1.00. The colour of spores was varies from brown to yellow except in isolate EPF-1, EPF-11 and EPF-13. The spores of these isolates were light grayish yellow, light green and light-yellow green in colour respectively. The spores of isolate EPF-5, EPF-6 and EPF15 were light yellow in colour while, spores of isolate EPF-8 were yellowish in colour. Ulhan et al., (2006) observed that conidia of Aspergillus spp. were 2.5-3.5 $\mu \mathrm{m}$ in diameter, globose to sub-globose, with wall smooth to slightly rough. While, Abdei et al., (2012) recorded conidia diameter of $3.2 \mu \mathrm{m}$ in $A$. tamarii.

\section{References}

Abdei, T.M. G., El Sheikh, H.H., Abdel, R.G.A. and Abdei, A.K.N.2012. Bioactivity of Certain Fungi on Root Knot Nematode. Journal of Jazan University-Applied Sciences Branch.2 (1):1-6.

Ali-Shtayeh, M.S., Mara, A.B.B. and Jamous, R. M. 2002. Distribution, occurrence 
and characterization of entomopathogenic fungi in agricultural soil in the Palestinian area. Mycopathologia. 156:235-244.

Alexopoulos, C. J., Mims, C. W. and Blackwell, M. 1996. Introductory Mycology, 4th edition, New York, John Willey \& Sons. pp. 105.

Berger, E.W. 1921. Natural enemies of scale insects and whiteflies in Florida. Florida State. Plant Breeding Quartely Bulletin. 5: 141-154.

Burges, H.D. 1981. Progress in the microbial control of pests in Microbial Control of Pests and Plant Diseases. (Ed. H.D. Burges), Academic Press, London, pp.1-6.

Domsch, K.H., Gams, W., Anderson. and Heidi, T. 1980. Compendium of soil fungi. Academic Press, London and New York.

Gupta, M., Kumari, M. and Ruby, G. 2012. Effect of various media types on the rate of growth of Aspergillus niger. Indian Journal of Fundamental and Applied Life Sciences ISSN. 2 (2):2231-6345.

Hajek, A.E. And Ledger, R.J. 1994. Interaction between fungal pathogens and insect hosts. Annual Review of Entomology. 39: 293-322.

Hina, A., Saleem, S. and Syeda, Q. U. N. 2013. Morphological identification of Aspergillus species from the soil of larkana district (sindh-pakistan). Asian Journal of Agriculture Biology. 1(3):105-117.

Indratiningsih., Endang, W., Ambar, P. and Shanti, A. S. 2013. Identification of Aspergillus species using morphological characteristic and the effect of temperature on the protease activity. International journal of biochemistry and biotechnology. 2(3):298-301.

Kirsten, F., Ge, R. F., Annette, B. J. and
William, O.H. H. 2014. The distribution of Aspergillus spp. opportunistic parasites in hives and their pathogenicity to honey bees. Veterinary Microbiology. 169: 203210

Maryam, N. A., Hassan. A., Sohrab, I. and Rasoul, Z. 2014. Isolation and characterization of entomopathogenic fungi from hibernating sites of Sunn Pest (Eurygaster integriceps) on Ilam Mountains, Iran. International Journal of Current Microbiology and Applied Sciences. 3(12): 314-325.

McClenny, N. 2005. Laboratory detection and identification of Aspergillus species by microscopic observation and culture: the traditional approach. Journal of Medical and Veternery Mycology. 43: S125-S128.

McCoy, C. W., Samson, R. A. and Boucias, D.G. 1988. Entomogenous fungi. In Handbook of Natural Pesticides, Boca, Raton, Fla: $\mathrm{Mr}$ ic Press. Microbial Insecticides, Part A, Entomogenous Protozoa and Fungi, C. M. Ignoffo and N. B. Mandava, eds. Vol. 5.

Nyongesa, B. W., Sheila, O., Vincent, A. 2015. Identification Key for Aspergillus species Isolated from Maize and Soil of Nandi County, Kenya. Advances in Microbiology. 5:205-229.

Odhiambo, B.O., Hunja, M. and Isabel, N.W.2013. Isolation and characterisation of Aflatoxigenic Aspergillus species from maize and soil samples from selected counties of Kenya. African Journal of Microbiology Research. 7(34):43794388.

Pasaru, F., Alam, A., Tutik, K., Mahfudz. and Shahabuddin. 2014. Prospective of entomopathogenic fungi associated with Helopeltis spp. (Hemipter: Miridae) on cacao plantation. 
International Journal of Current Research and Academic Review. 2(11):227-234.

Pasteur, L. 1874. Observations (au sujet des conclusions de M. Dumas) relatives au phylloxera. Comptes rendus hebdomadaires des seances de 1 Academie des Sciences. 79 : 12331234.

Raper, K.B. and Fennell, D. 1965 . The genus Aspergillus. Williams and Wilkins
Company.

Shin, T.Y., Jae -Bang, C., Sung- Min, B., Hyun-Na, K. and Soo-Dong, D. 2010. Study on selective media for Isolation of entomopathogenic fungi. International Journal of Industrial Entomology. 20(1):7-12.

Ulhan, S., Rasime, D., Ahmet, A. and Cengiz, B. E. K. 2006. Turkistan Journal of Botany. 30:95-104.

\section{How to cite this article:}

Sable, S.B., P.B. Deore, H.V. Deshmukh, H.N. Markad and Jejurkar, G.B. 2019. Variability in Morphology and Growth Characteristics of Different Isolates of Entomopathogenic Fungi Managing the Mealy Bugs Maconellicocus hirsutus. Int.J.Curr.Microbiol.App.Sci. 8(03): 21562165. doi: https://doi.org/10.20546/ijcmas.2019.803.258 